\title{
IMPLEMENTASI PRINSIP PARIWISATA BERBASIS KOMUNITAS DI DESA WISATA NGLINGGO YOGYAKARTA
}

\author{
Rosdiana Pakpahan \\ Universitas Pelita Harapan \\ Email: rosdiana.pakpahan@uph.edu
}

\begin{abstract}
This study is carried out in Nglinggo rural tourism destination located in Pagerharjo village, Samigaluh sub-district, Kulon Progo regency in Yogyakarta. This research is aimed at revealing the application CBT principles implemented in the management of the rural tourism attraction as well as finding supporting factors and obstacles on the application of the CBT principles. This study also traces why such factors and obstacles occur. This research applies both qualitative and quantitative techniques in obtaining primary and secondary data. The primary data is collected by questionnaires, indepth interview and observation, while the secondary data is obtained mainly from local authority's website of Office of Tourism of Kulon Progo Regency.This study suggests that local people are aware on the importance of involvement in managing their village as an attraction. Meanwhile, supporting factors of the application of CBT principles are natural resources, local people cohesion, contribution to local people, local community involvement, existence of supporting institution, management commitment, and local authority's support. On the other hand, obstacle found in the application of the CBT principles are education and people readiness.
\end{abstract}

Key words: implementation, community-based tourism principles, supporting factors, obstacles.

\section{PENDAHULUAN}

\section{Latar Belakang}

Dariwisata merupakan suatu industri yang besar dan salah 1 satu penyumbang devisa Negara. Menurut World Tourism 
Organization (WTO), pariwisata telah mampu menyumbangkan pendapatan lebih dari US $\$ 3,5$ triliun atau $6 \%$ dari pendapatan kotor dunia. Sektor pariwisata Indonesia terus mencatat perkembangan positif yang signifikan sejak tahun 2010. Pada tahun 2010 jumlah wisatawan mancanegara tercatat sebanyak 7 juta orang, tetapi tahun 2015 naik menjadi 10,4 juta orang. Destinasi pariwisata juga terus berbenah yang ditandai oleh penataan dan penyelenggaraan events penarik wisatawan. Pemerintah juga menetapkan 10 destinasi pariwisata prioritas yang bertujuan untuk mempercepat kelengkapan dan peningkatan mutu infrastruktur dan layanan pariwisata.

Konsep CBT relevan dengan pengembangan atraksi pariwisata di Indonesia. Ada dua alasan yang diajukan untuk mendukung argumentasi tersebut. Pertama adalah bahwa fokus CBT adalah masyarakat lokal. Masyarakat lokal berperan sebagai pemilik sumberdaya sekaligus aktor dalam pengembangan sumberdaya tersebut. Di sini, budaya lokal memainkan peran yang sangat menentukan. Budaya dalam arti luas menjadikan produk pariwisata Indonesia sangat beragam. Oleh karena itu CBT mampu memperkuat posisi masyarakat dalam perkembangan pariwisata. Kedua, fakta menunjukkan bahwa budaya merupakan atraksi yang diminati oleh hampir dua pertiga wisatawan mancanegara di Indonesia. Menerapkan prinsip CBT dengan sendirinya akan meningkatkan daya tarik budaya dalam aktivitas pariwisata.

Gambaran ideal CBT tersebut perlu diuji berdasarkan bukti empirik. Ia juga merupakan basis analisis terhadap perkembangan sejumlah desa-desa atau kampung wisata yang diklaim sukses, atau sebaliknya gagal, meningkatkan kesejahteraan masyarakat. Sejauh ini klaim tentang keberhasilan dan atau kegagalan desa atau kampung wisata belum dikaji secara komprehensif, terutama dengan menggunakan pendekatan CBT.

Ada pertanyaan yang layak diajukan sehubungan dengan pertambahan jumlah desa atau kampung wisata, khususnya di Yogyakarta, sampai sekarang berkisar 122 desa wisata. Di satu 
sisi pertambahan itu mampu menggerakkan ekonomi perdesaan secara signifikan, antara lain berkat diversifikasi pekerjaan. Di sisi lain, tidak sedikit desa wisata dikembangkan dengan investasi dari luar desa, seperti di Kulon Progo. Selain itu, perkembangan desa wisata juga belum sepenuhnya melibatkan penduduk setempat. Pada kasus-kasus tertentu ia bahkan memicu konflik antar-warga lokal seperti yang terjadi pada desa wisata Bejiharjo.

Artinya, banyak desa-desa wisata yang dikembangkan melalui sponsor pemerintah dan dorongan investasi dan manajemen pihak luar desa. Meskipun demikian, sekali lagi analisis yang cermat tentang hal itu belum banyak dilakukan, khususnya berkaitan dengan penerapan prinsip CBT. Klaim partisipasi masyarakat, pengelolaan sumberdaya lokal, manajemen usaha kecil, distribusi hasil yang adil, dan sebagainya sering diungkapkan dalam wacana, namun seberapa sahih klaim itu dalam praktek tampaknya masih belum terlacak secara jelas.

\section{LANDASAN TEORI}

Istilah CBT muncul sebagai bentuk alternatif pariwisata yang didominasi oleh pariwisata massal yang menimbulkan banyak masalah di destinasi pariwisata (Suansri 2003: 11). Pariwisata (massal) diklaim membawa dampak negatif yang condong mengeksploitasi sumberdaya ekonomi, sosial, budaya dan lingkungan di destinasi pariwisata, sehingga diperlukan bentuk atau tipe baru pariwisata. Oleh sebab itu, konsep asal CBT berkaitan dengan konsep keberlanjutan, pemberdayaan, dan kemandirian (Giampiccoli dan Kalis 2012: 174). Para ahli menggunakannya sebagai istilah to describe a variety of activities that encourage and support a wide range of objectives in economic and social development and conservation. Oleh sebab itu ia juga diartikan sebagai tipe pariwisata yang menitikberatkan keberlanjutan lingkungan, sosial dan budaya kedalam satu kemasan. Ia dikelola dan dimiliki oleh dan untuk masyarakat dengan tujuan untuk memungkinkan pengunjung meningkatkan kesadaran dan belajar 
tentang masyarakat dan cara hidup masyarakat lokal. Penekanan pada peran komunitas lokal dalam CBT menjadikannya sebagai pariwisata yang memperhitungkan dan menempatkan keberlanjutan lingkungan, sosial dan budaya, diatur dan dimiliki oleh komunitas, serta untuk komunitas. Sejumlah ahli mencoba menerjemahkan prinsip tersebut ke dalam suatu kerangka yang lebih aplikatif dan merupakan simplifikasi dari kesepuluh prinsip ideal tersebut.

Pertama, CBT sangat tergantung pada konservasi alam dan mampu mencegah degradasi lingkungan. Disini diasumsikan bahwa CBT mengandalkan keunikan lingkungan sebagai atraksi pariwisata. (UNEP dan WTO 2005; Suansri 2003; Brohman, 1996). Kedua, terciptanya lapangan pekerjaan di bidang pariwisata. Jika diimplementasikan dengan baik, pariwisata berbasis masyarakat dapat memberikan manfaat ekonomi yaitu dengan meningkatkan pendapatan masyarakat lokal melalui keuntungan usaha dan kesempatan kerja, mengentaskan kemiskinan, memulihkan kondisi ekonomi dan memperbaiki infrastruktur. (Toressa dan Momsen 2004). Penggunaan tenaga lokal juga memiliki keuntungan lain, yakni efek psikologis bagi masyarakat dalam bentuk kebanggaan sebagai pemilik sumberdaya pariwisata setempat, sekaligus alat untuk meredam potensi kecemburuan sosial (Damanik dan Weber 2006).

Ketiga, partisipasi masyarakat maksudnya memosisikan masyarakat sebagai partisipasi aktif dalam pengembangan pariwisata (Suansri 2003; Nasikun 2000). Keempat, didasarkan pada prinsip edukasi (pendidikan)/sumber daya manusia. Pariwisata berbasis masyarakat dapat meningkatkan kualitas SDM lokal melalui program pelatihan dan pendidikan, mendukung organisasi masyarakat lokal dalam hal meningkatkan kapasitas, membangun jejaring dan keterlibatan mereka dalam pengembangan pariwisata di daerahnya dan memungkinkan terciptanya tata kelola kepariwisataan yang baik melalui keterlibatan dan pastisipasi masyarakat dalam perencanaan di segala tingkatan (Suansri 2003).

132 JUMPA Volume 05, Nomor 01, Juli 2018 
Kelima, hal lain dalam mengelola dan mengembangkan CBT yang perlu diperhatikan adalah mempertahankan unique values yang berupa adat istiadat, upacara tradisional, kepercayaan, seni pertunjukan tradisional, dan seni kerajinan khas yang dimiliki oleh masyarakat dikawasan tersebut. (Demartoto 2009). Di beberapa destinasi pariwisata yang dikelola oleh komunitas, wisatawan menginap di rumah-rumah penduduk, belajar membatik, menari dan lebih intens menyelami living culture masyarakat setempat. Mereka tidak segan-segan menanggalkan identitas aslinya, sebagai suatu cara untuk memahami sekaligus memperoleh pengalaman yang unik dan utuh dari kegiatan tersebut (Putra 2011).

\section{METODE PENELITIAN}

Penelitian ini menggunakan pendekatan gabungan kualitatif dan kuntitatif. Metode yang digunakan dalam penelitian ini adalah metode survey, observasi dan wawancara mendalam. Indikator prinsip pariwisata berbasis masyarakat dikembangkan untuk menjadi pernyataan dan pertanyaan yang berbasis prinsip lingkungan, prinsip ekonomi, prinsip partisipasi masyarakat, prinsip SDM/Pendidikan dan prinsip budaya. Sampel diperoleh dari masyarakat Nglinggo, berjumlah 82 orang dan 16 informan yang ditentukan dengan menggunakan teknik purposive sampling. Penelitian dilakukan di Desa Wisata Nglinggo pada bulan Januari 2017 hingga April 2017. Data dianalisis dengan metode analisis deskriptif kualitatif dan kuantitatif.

\section{HASIL PENELITIAN DAN PEMBAHASAN}

Desa Wisata Nglinggo merupakan sebuah desa yang terletak di kecamatan Samigaluh, Kabupaten Kulon Progo, Yogyakarta. Desa ini sangat unik karena letaknya di kaki gunung tidak seperti desa-desa pada umumnya. Terletak di pegunungan Menoreh membuat daerah ini dingin dan sejuk sehingga banyak orang yang ingin mengunjungi objek ini. 
Desa Wisata Nglinggo mempunyai potensi wisata alam, budaya dan wisata edukasi, seperti kebun teh, Bukit Isis, Gunung Jaran, Air Terjun Watu Jonggol, Tari Lengger, pembuatan gula, kopi, teh dan membatik. Desa Wisata Nglinggo juga memiliki wisata off road dengan trek pendek dan panjang sampai ke Borobudur. Sebagai sebuah desa wisata yang tergolong masih baru, Desa Wisata Nglinggo sudah mendapatkan prestasi yang terbilang baik. Hal ini dibuktikan dengan terpilihnya desa ini menjadi juara 2 (dua) desa wisata tingkat umum dan juara 1 (satu) desa wisata spesial pengelolaan oleh Dinas Pariwisata Pemuda dan Olahraga Kulon Progo pada tahun 2015.

Untuk menuju lokasi Desa Wisata Nglinggo selain menggunakan petunjuk GPS pengunjung juga dapat memperoleh informasi dari papan petunjuk arah yang terdapat di sepanjang jalan menuju Nglinggo yang dimulai dari petunjuk arah pasar Plono. Desa Wisata Nglinggo dapat ditempuh melalui beberapa jalur karena letaknya berada diperbatasan antara Purworejo dan Magelang. Jika datang dari Yogyakarta, dapat melalui Jalan Godean lurus sampai ke wilayah Kulonprogo hingga mencapai Perempatan Kentheng Nanggulan. Dari perempatan ambil ke kanan (ke utara) susuri jalan hingga Perempatan Dekso. Dari Perempatan Dekso tersebut belok kearah barat menuju Desa Pagerharjo sampai Pasar Plono dan langsung belok kanan hingga sampai ke Desa Wisata Nglinggo.

Jika anda datang dari arah Borobudur, sebaiknya mengambil jalan Borobudur-Mendut. Pertigaan Candi Mendut ambil arah kanan menuju Kalibawang hingga Perempatan Dekso. Sampai di Perempatan Dekso, belok kanan kearah Samigaluh - Plono terminal terakhir (Plono) kemudian belok kanan dan sampailah di desa wisata Nglinggo. Peta wisata desa wisata Nglinggo dapat dilihat dibawah ini. 


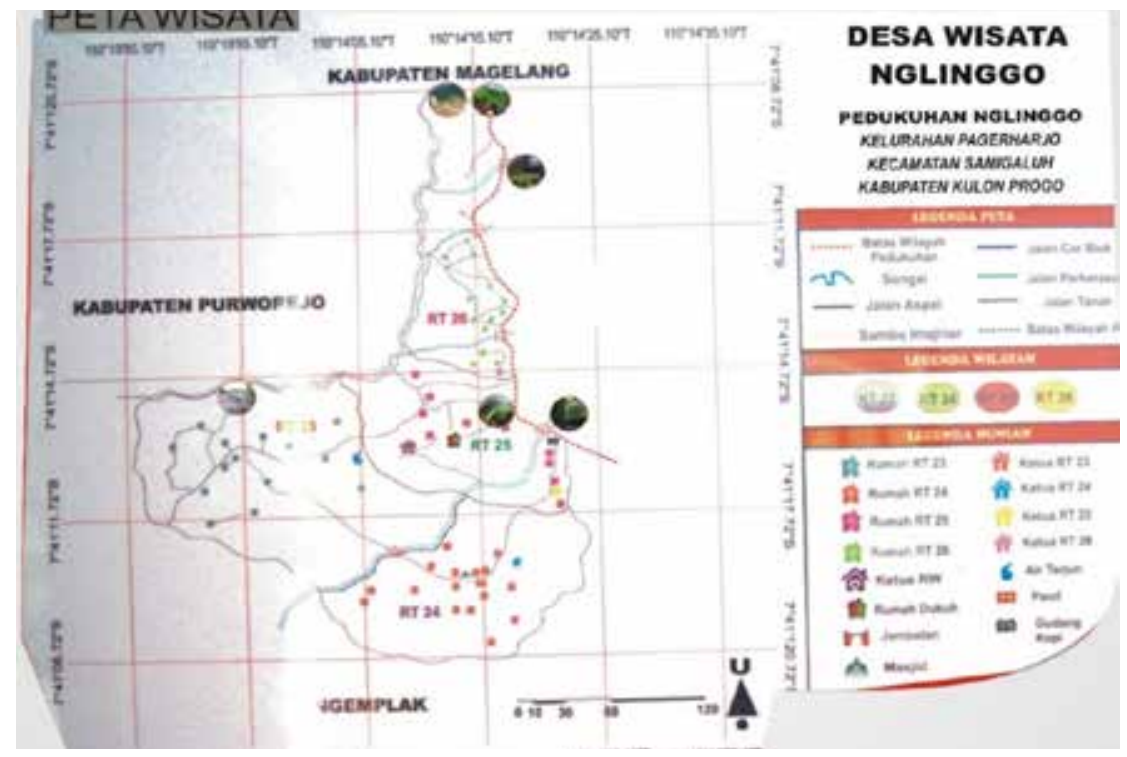

Foto 1 Peta Desa Wisata Nglinggo Sumber: Sekretariat Desa Wisata Nglinggo

Desa Wisata ini diberi nama Desa Wisata Nglinggo selanjutnya disebut (DWL), yang awal didirikan pada tanggal, 9 November 2004 di Dusun Nglinggo Barat Desa Pagerharjo Kecamatan Samigaluh Kabupaten Kulon Progo. Keberadaan Desa Wisata Nglinggo tidak terlepas dari peristiwa sejarah Pangeran Diponegoro. Pada jaman itu tiga orang pengikut setia Pangeran Diponegoro, yang bernama Ki Linggomanik, Ki Dalem Tanu dan Gagak Roban mendapatkan wilayah Menoreh, yang sekarang meliputi Kulon Progo, Magelang dan Purworejo, sebagai wilayah konsentrasi bergerilyanya melawan penjajah Belanda. Sebagai pusat perjuangan dipilihlah lokasi yang berada di puncak Pegunungan Menoreh. Sebuah tempat yang strategis untuk menyusun strategi untuk mengamati pergerakan penjajah Belanda. Tempat ini kemudian dinamakan Nglinggo diambil dari nama pemimpinnya yaitu Ki Linggo Manik. Sebagai bukti sejarah, saat ini bisa menjumpai adanya tiga petilasan yang banyak ditumbuhi pepohonan besar berumur ratusan tahun. 

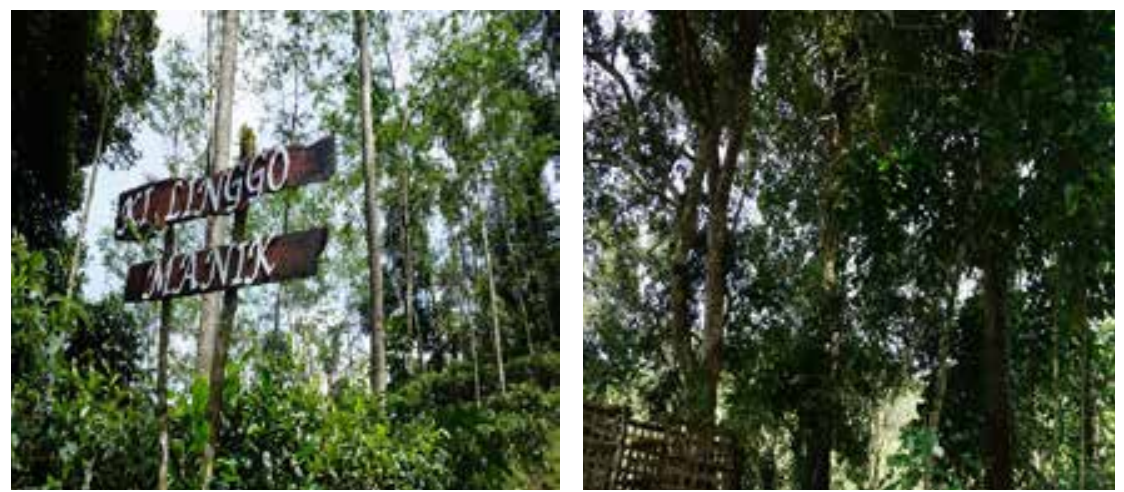

Foto 2 Pohon Dengan Umur Ratusan Tahun

Sumber : Dokumentasi Pribadi

1. Keutuhan Penerapan Prinsip Pariwisata Berbasis Komunitas

a. Prinsip Lingkungan

Prinsip lingkungan diukur dari tiga indikator, yaitu penerapan konsep daya dukung lingkungan, pembuangan sampah yang ramah lingkungan dan penerapan konservasi pada objek wisata tersebut. Seluruh kegiatan atau aktivitas yang dilakukan akan berdampak terhadap lingkungan, salah satunya kegiatan pariwisata. Aktivitas pariwisata akan menghasilkan dampak terhadap lingkungan baik positif maupun negatif. Hasil dari tanggapan responden mengenai aspek lingkungan tertera pada tabel dibawah ini.

Tabel 1 Prinsip Lingkungan

\begin{tabular}{|c|c|c|c|}
\hline Aspek & $\begin{array}{c}\text { Skor Empiris } \\
(\mathrm{a})\end{array}$ & Skor Maksimal (b) & $\begin{array}{c}\text { Kutuhan Penerapan Prinsip CBT } \\
(\mathrm{c}=\mathrm{a} / \mathrm{b} \times 100)\end{array}$ \\
\hline $\begin{array}{c}\text { Lingkun- } \\
\text { gan }\end{array}$ & 1044 & $(3 \times 5 \times 82)=1230$ & $1044 / 1230 \times 100=84,9 \%$ \\
\hline
\end{tabular}

Sumber: Diolah dari Data Primer.

Berdasarkan tabel diatas terlihat bahwa penerapan prinsip lingkungan sudah pada level tinggi. Untuk konservasi terlihat dari upaya pemerintah dan masyarakat untuk menjaga kelestarian lingkungan termasuk di setiap objek wisata. Dengan adanya batasan-batasan yang dibuat untuk lokasi yang bisa dan yang 
tidak bisa dilalui di area objek tersebut membuat objek tersebut semakin lestari dan terjaga.

Kelestarian lingkungan sangat mempengaruhi keberlanjutan objek itu sendiri. Terciptanya pariwisata berbasis komunitas dapat diindikasikan melalui beberapa gejala dan peran masyarakat dalam menentukan sektor pariwisata yang dibangun di desa ini. Pada dasarnya masyarakat tidak terlalu menyadari bahwa apa yang mereka lakukan itu merupakan pelaksanaan dari pariwisata berbasis komunitas. Masyarakat (guru) sering mengajak anak-anak sekolah untuk belajar menanam pohon dan cara merawat kebun sehingga anak-anak dari dini sudah diajarkan untuk memelihara lingkungan disekitar Desa Wisata Nglinggo, seperti terlihat pada gambar di bawah ini.

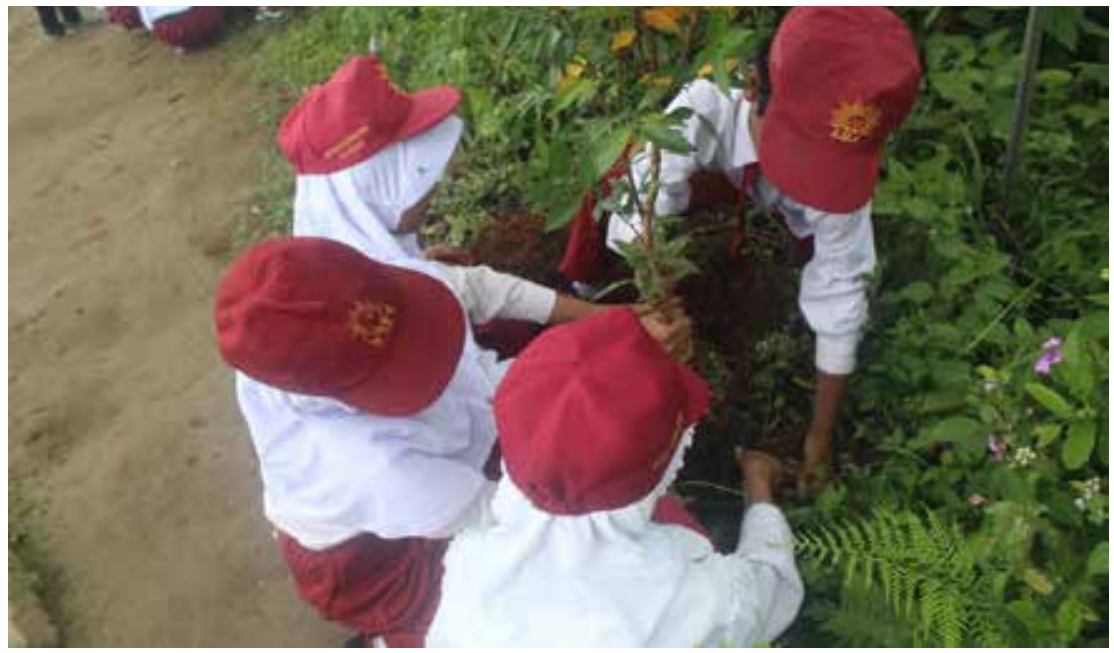

Foto 3 Belajar Menanam Pohon Demi Kelestarian Lingkungan Sumber: Dokumentasi Pribadi

Masyarakat Desa Wisata Nglinggo sudah semakin sadar akan pentingnya kebersihan terbukti dari gotong royong yang mereka lakukan merupakan inisiatif dari masyarakat Nglinggo. Lingkungan yang bersih akan membuat wisatawan nyaman ketika berkunjung. Hal ini membantu Desa Wisata Nglinggo dalam pemasaran yang dilakukan dari mulut ke mulut oleh wisatawan tersebut. Dibawah ini terdapat gambar 4 tempat pembuangan 
sampah yang terbuat dari bambu.
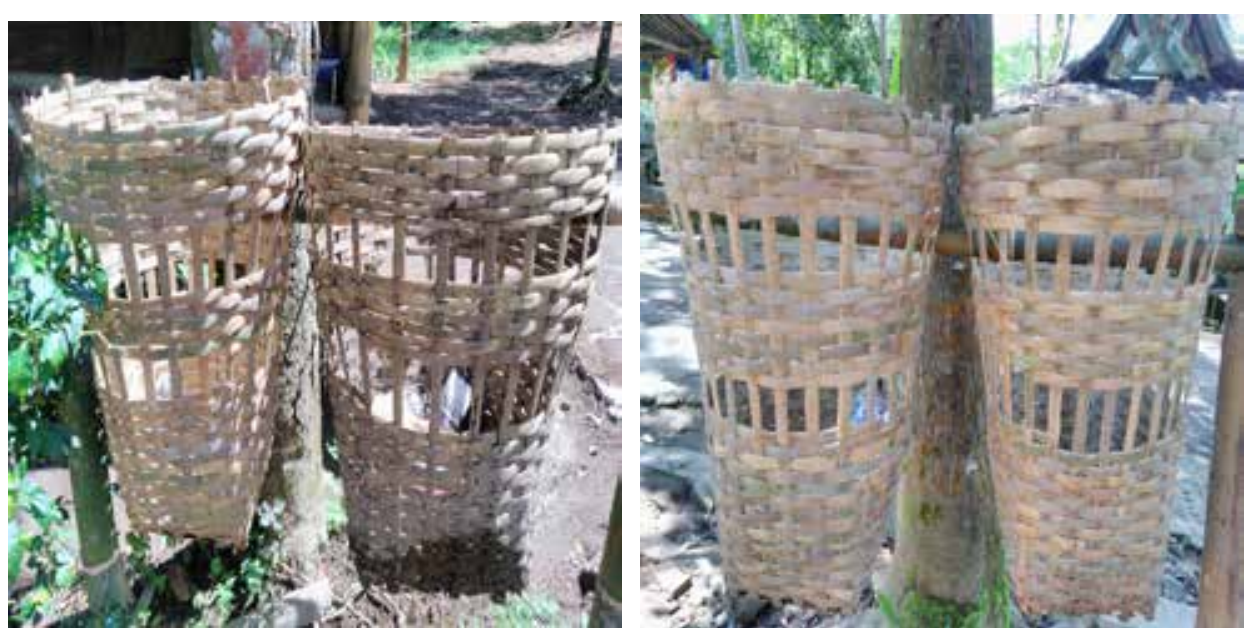

Foto 4 Tempat Sampah yang Terbuat Dari Bambu

Sumber : Dokumen Pribadi

\section{b. Prinsip Ekonomi}

Prinsip ekonomi diukur dengan beberapa indikator seperti tersedianya lapangan pekerjaan baik industri produksi rumah tangga maupun penjualan dan peningkatan kualitas hidup. Jika diimplementasikan dengan baik, maka masyarakat akan merasakan keuntungan baik ekonomi maupun psikologi. Melalui kuesioner yang sudah dibagikan dapat dilihat hasilnya pada tabel dibawah ini.

Tabel 2 Prinsip Ekonomi

\begin{tabular}{|c|c|c|c|}
\hline Aspek & $\begin{array}{c}\text { Skor Empiris } \\
\text { (a) }\end{array}$ & $\begin{array}{c}\text { Skor Maksimal } \\
(\mathrm{b})\end{array}$ & $\begin{array}{c}\text { Kutuhan Penerapan Prinsip CBT } \\
(\mathrm{c}=\mathrm{a} / \mathrm{b} \times 100)\end{array}$ \\
\hline Ekonomi & 1363 & $(4 \times 5 \times 82)=1640$ & $1363 / 1640 \times 100=83,1 \%$ \\
\hline
\end{tabular}

Sumber: Diolah dari Data Primer.

Berdasarkan tabel diatas terlihat bahwa prinsip ekonomi sudah pada tahap persentase tinggi. Lapangan pekerjaan yang tercipta sebagai dampak adanya Desa Wisata Nglinggo adalah pemandu, driver untuk offroad, juru masak, industri rumah tangga, pedagang (warung), tukang, serta menjadi anggota kelompok 
sadar wisata. Para petani yang tadinya hanya pergi ke kebun dan merumput, sekarang mereka mendapat pekerjaan sampingan yaitu berjualan maupun memproduksi makanan untuk dititipkan di warung-warung sekitar Desa Wisata Nglinggo.

Penggunaan dana dari penghasilan pariwisata digunakan untuk belanja bahan-bahan yang diperlukan dalam pengembangan desa wisata, baik berupa makanan, untuk keperluan seni serta yang lainnya yang berkaitan dengan Desa Wisata Nglinggo. Selain itu hasil dari pariwisata disumbangkan untuk masyarakat melalui iuran yang sekarang semuanya gratis khususnya merti dusun atau saparan.

\section{c. Prinsip Partisipasi Masyarakat}

Selain berkontribusi dalam pelestarian lingkungan, Desa Wisata Nglinggo merupakan desa wisata yang melibatkan seluruh lapisan masyarakat dalam pengembangan desa wisata tersebut baik secara langsung maupun tidak langsung. Pemuda karang taruna aktif dalam pengembangan Desa Wisata Nglinggo, mereka yang paling aktif dalam menjalankan operasional pariwisata. Ibu rumah tangga sebagian menjadi juru masak ketika wisatawan datang, baik untuk makanan yang dikonsumsi oleh wisatawan maupun mereka yang ingin belajar membuat kopi, gula aren dan teh (wisata edukasi). Pada tabel (3) merupakan hasil dari kuesioner yang dibagikan kepada masyarakat dalam hal partisipasi masyarakat.

Tabel 3 Prinsip Partisipasi Masyarakat

\begin{tabular}{|c|c|c|c|}
\hline Aspek & $\begin{array}{c}\text { Skor Empiris } \\
\text { (a) }\end{array}$ & $\begin{array}{c}\text { Skor Maksimal } \\
(\mathrm{b})\end{array}$ & $\begin{array}{c}\text { Kutuhan Penerapan Prinsip CBT } \\
(\mathrm{c}=\mathrm{a} / \mathrm{b} \times 100)\end{array}$ \\
\hline $\begin{array}{c}\text { Partisipasi } \\
\text { Masyarakat }\end{array}$ & 1401 & $(4 \times 5 \times 82)=1640$ & $1363 / 1640 \times 100=85,4 \%$ \\
\hline
\end{tabular}

Sumber: Diolah dari Data Primer.

Berdasarkan tabel diatas terlihat bahwa prinsip partisipasi masyarakat memiliki empat pertanyaan. Masyarakat Nglinggo berpartisipasi dalam banyak hal terhadap pengembangan Desa 
Wisata Nglinggo, misalnya dalam hal kebersihan. Seluruh masyarakat Nglinggo melakukan aksi gotong royong setiap hari minggu tanpa terkecuali. Mereka sudah mulai sadar bahwa desa mereka sudah mulai dikenal oleh masyarakat luas. Tidak hanya dalam hal kebersihan, masyarakat Nglinggo juga dilibatkan dalam hal rapat yang dilakukan oleh anggota kelompok sadar wisata.

Partisipasi masyarakat juga terlihat dalam gotong royong yang dilakukan, misalnya ada tanah longsor sebagian besar warga langsung turun ke lapangan tanpa menunggu perintah dari kepala dukuh/ketua kelompok sadar wisata. Mereka ingin desa mereka semakin dikenal oleh masyarakat luas dan tetap mendapat perhatian dari pemerintah. Salah satu contoh gotong royong yang dilakukan terlihat pada gambar 5 dibawah ini.

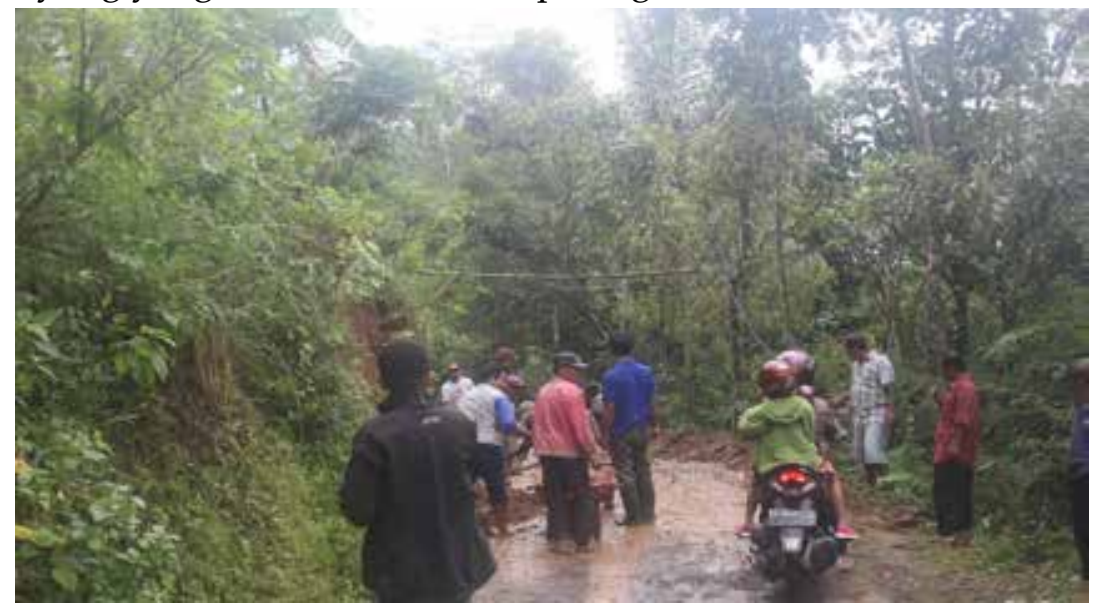

Foto 5 Aksi Gotong Royong Ketika Tanah Longsor

Sumber : Dokumen Pribadi

Paket wisata yang ditawarkan kepada pengunjung beragam jenisnya, dan pengunjung bisa memilih satu atau seluruh paket wisata. Wisatawan yang datang secara berkelompok biasanya memilih paket edukasi pembuatan teh, kopi dan gula aren. Harga per kelompok biasanya dikenakan sebesar Rp 50.000. Hal ini ditegaskan oleh dan terlihat seperti gambar 6 dan 7 di bawah ini:

"Disini ada atraksi edukasi teh, kopi dan gula aren, paketan tersebut sudah termasuk mulai dari pemetikan sampai dengan pengolahan" (Mas MK, 33 thn) 


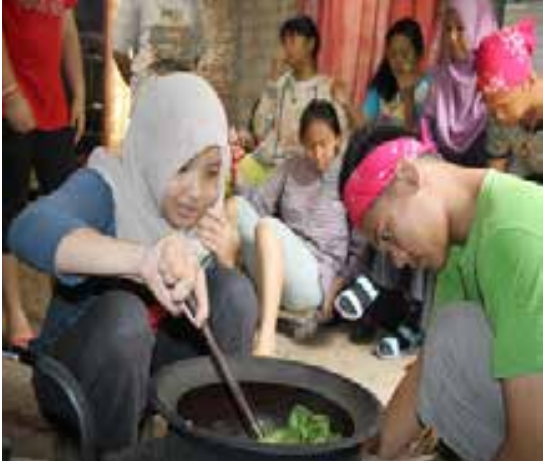

Foto 6 Proses Pengolahan Gula Aren. Sumber : Dokumen Pribadi

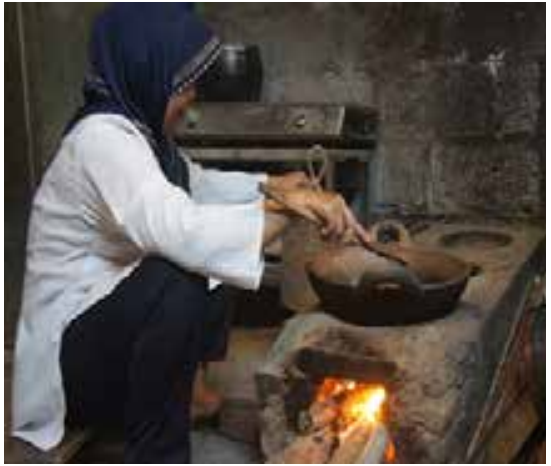

Foto 7 Proses Pengolahan Teh Sumber : Dokumen Pribadi

\section{d. Prinsip SDM/Pendidikan}

Prinsip pendidikan/SDM diukur dari beberapa indikator, seperti pelatihan bagi anggota kelompok sadar wisata begitu juga dengan masyarakat yang mempunyai industri rumah tangga atau warung guna meningkatkan kualitas. Pada tabel 4 merupakan hasil dari kuesioner yang dibagikan kepada masyarakat pada aspek SDM/Pendidikan.

Tabel 4 Prinsip SDM/Pendidikan

\begin{tabular}{|c|c|c|c|}
\hline Aspek & Skor Empiris (a) & $\begin{array}{c}\text { Skor Maksimal } \\
(\mathrm{b})\end{array}$ & $\begin{array}{c}\text { Kutuhan Penerapan Prinsip CBT } \\
(\mathrm{c}=\mathrm{a} / \mathrm{b} \times 100)\end{array}$ \\
\hline $\begin{array}{c}\text { SDM/ } \\
\text { Pendidikan }\end{array}$ & 1371 & $(4 \times 5 \times 82)=1640$ & $1363 / 1640 \times 100=83,6 \%$ \\
\hline
\end{tabular}

Sumber: Diolah dari Data Primer.

Berdasarkan tabel diatas terlihat bahwa prinsip SDM/ Pendidikan memiliki empat pertanyaan. Hal ini menunjukkan menurut mayoritas responden, kemampuan kelompok sadar wisata dan masyarakat Nglinggo dalam menerapkan prinsipprinsip pariwisata berbasis masyarakat (CBT) pada variabel SDM/ Pendidikan adalah tinggi. Desa Wisata Nglinggo sudah pernah melakukan pelatihan bagi anggota komunitas baik di desa wisata sendiri bahkan anggota di ajak oleh ketua kelompok sadar wisata untuk mengunjungi desa wisata lainnya sehingga bisa menjadi bahan contoh bagi Desa Wisata Nglinggo. 
Pengembangan Desa Wisata Nglinggo yang melibatkan seluruh lapisan masyarakat telah melakukan pelatihan terhadap kelompok sadar wisata maupun terhadap masyarakat. Pengembangan tersebut belum menjadi agenda rutin oleh Desa Wisata Nglinggo, dikarenakan SDM yang masih kurang. Pelatihan yang dilakukan terhadap anggota kelompok sadar wisata dari pemerintah dan dari Fakultas Ilmu dan Budaya Universitas Gadjah Mada merupakan sebuah bentuk sumbangan kepada Desa Wisata Nglinggo.

\section{e. Prinsip Budaya}

Prinsip budaya diukur dari beberapa indikator, seperti pertukaran budaya dan melestarikan budaya yang ada. Desa Wisata Nglinggo memiliki kebudayaan yang hampir punah dan dengan adanya desa wisata kebudayaan itu muncul dan aktif kembali yaitu Tari Lengger Tapeng. Tari Lengger Tapeng merupakan kesenian adat yang ada di Desa Wisata Nglinggo. Durasi pementasan Lengger mulai dari 30 menit hingga 5 jam. Pada tabel 5 merupakan hasil dari kuesioner yang dibagikan kepada masyarakat pada aspek budaya.

Tabel 5 Prinsip Budaya

\begin{tabular}{|c|c|c|c|}
\hline Aspek & $\begin{array}{c}\text { Skor Empiris } \\
(\mathrm{a})\end{array}$ & Skor Maksimal (b) & $\begin{array}{c}\text { Kutuhan Penerapan Prinsip CBT } \\
(\mathrm{c}=\mathrm{a} / \mathrm{b} \times 100)\end{array}$ \\
\hline Budaya & 1406 & $(4 \times 5 \times 82)=1640$ & $1363 / 1640 \times 100=85,7 \%$ \\
\hline
\end{tabular}

Sumber: Diolah dari Data Primer.

Berdasarkan tabel di atas terlihat bahwa prinsip budaya memiliki empat pertanyaan. Hal ini menunjukkan masyarakat Desa Wisata Nglinggo mempertahankan budaya dengan cara melakukan latihan rutin dan pertunjukan ketika ada acara-acara yang dilakukan di Desa Wisata Nglinggo. Seperti ungkapan dari mas Rr, 26th (16 Februari 2017) sebagai anggota kelompok sadar wisata juga sebagai penari berpendapat:

"Cara kami mempertahankan budaya adalah dengan melakukan latihan menari dengan tekun, dengan seperti itu kami akan siap menampilkan 
Implementasi Prinsip Pariwisata Berbasis Komunitas di Desa Wisata Nglinggo...

budaya kami kapan saja dan kalau ada acara-acara di desa, kami selalu tampil walaupun tidak permintaan pengunjung. Wisatawan yang datang juga tidak menjadi penghambat bagi kami untuk mewujudkan budaya kami, dan kami sebagai pemuda sering diingatkan oleh orangtua untuk tidak mengikuti cara berpakaian yang kurang bagus/baik dari tamu yang datang"( $\mathbf{R r}$, 26th)

Hampir semua konsep CBT dalam hal budaya telah diterapkan oleh pengelola. Aspek yang perlu dimaksimalkan lagi adalah masyarakat menjalin komunikasi yang baik terhadap wisatawan, budaya/pertunjukan tradisional harus dijaga dan dikembangkan lewat latihan/pertunjukan tanpa harus adanya permintaan dari wisatawan. Masyarakat mengharapkan adanya Desa Wisata Nglinggo dapat melestarikan budaya yang ada seperti Tari Lengger Tapeng. Hal ini dikarenakan adanya dana yang dapat digunakan masyarakat untuk membiayai pertunjukan tari ini. Tidak harus memberikan upah pada penarinya, tetapi minimal kebutuhan operasionalnya dapat ditutupi sehingga penari tidak perlu mengeluarkan biaya, artinya kontribusi didapatkan dari eksistensi Desa Wisata Nglinggo.

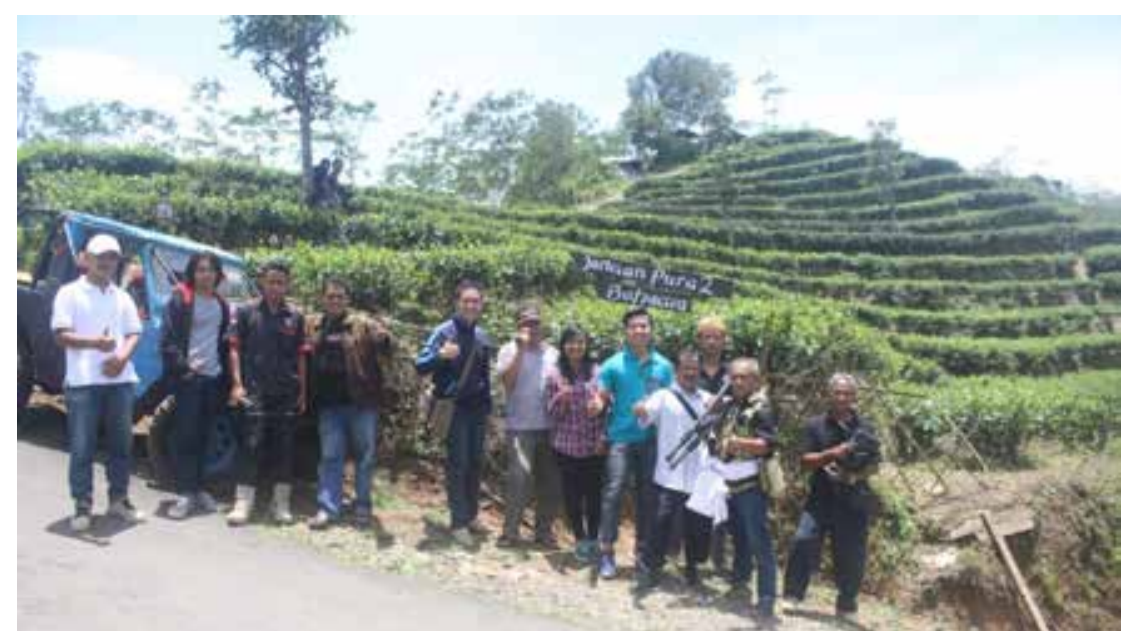

Foto 8 Kebun Teh Nglinggo

Sumber: Dokumentasi Pribadi

Kawasan Desa Wisata Nglinggo memiliki keunggulan komparatif dibandingkan obyek wisata lain di Daerah Wisata 
Yogyakarta yakni keberadaan perkebunan teh. Perkebunan teh yang dimiliki relatif luas sehingga nampak terhampar hijau di perbukitan yang luas. Bukit-bukit yang dibuat terasering merupakan spot foto yang sempurna.

2. Faktor Pendukung dan Faktor Penghambat Penerapan Prinsip Pariwisata Berbasis Komunitas

Terdapat beberapa faktor yang menjadi faktor pendukung dan faktor penghambat, diantaranya:

a. Fakor yang menjadi pendukung dalam penerapan prinsip CBT yakni, sumber daya alam, kohesifitas masyarakat, keterlibatan masyarakat lokal, adanya kelembagaan, komitmen pengelola dan dukungan pemerintah.

b. Sedangkan faktor yang menjadi penghambat penerapan prinsip CBT yakni, pendidikan dan kesiapan masyarakat.

\section{PENUTUP}

Berdasarkan pembahasan yang berkaitan dengan impementasi prinsip-prinsip CBT dalam pengembangan Desa Wisata Nglinggo dan faktor pendukung maupun faktor penghambat penerapan prinsip CBT di desa Wisata Nglinggo, dapat disimpulkan beberapa hal sebagai berikut:

1. Pengembangan Desa Wisata Nglinggo mengunakan pendekatan pariwisata berbasis masyarakat. Masyarakat dilibatkan dalam pengembangan Desa Wisata Nglinggo baik dalam kegiatan perencanaan, pelaksanaan sampai dengan distribusi. Masyarakat juga merasakan keuntungan yang didapatkan dari pariwisata baik secara langsung maupun secara tidak langsung.

2. Prinsip pariwisata berbasis masyarakat, yakni dari aspek lingkungan $(84,9 \%)$, aspek ekonomi $(83,1 \%)$, partisipasi masyarakat $(85,4 \%)$, SDM/pendidikan $(83,6 \%)$ dan aspek budaya $(85,7 \%)$ telah diterapkan dengan hasil seperti tertera diatas.

3. Secara keseluruhan prinsip pariwisata berbasis masyarakat (CBT) telah diterapkan sebesar $84,54 \%$. Hal ini menunjukkan 
bahwa secara keseluruhan prinsip-prinsip pariwisata berbasis masyarakat (CBT) telah diterapkan dalam pengembangan Desa Wisata Nglinggo.

4. Fakor yang menjadi pendukung dalam penerapan prinsip CBT yakni, sumber daya alam, kohesifitas masyarakat, keterlibatan masyarakat lokal, adanya kelembagaan, komitmen pengelola dan dukungan pemerintah. Sedangkan faktor yang menjadi penghambat penerapan prinsip CBT yakni, pendidikan dan kesiapan masyarakat.

\section{Daftar Pustaka}

Arida, N. S. 2016. Dinamika Ekowisata Tri Ning Tri di Bali. Denpasar: Pustaka Larasan.

Brohman, 1996. "New Directions in Tourism for Third World Development", Ann. of Tour. Res., 23(1), hal. 43-70

Cater, E. 1996. Community Involvement in Third World Ecotourism. (Geogprahical Papers, Series B), Dept. Geography, University of Reading. Bandingkan: Saxena, G., Clark, G., Oliver, T \& Ilbery, B. 2007. Conceptualizing Integrated Rural Tourism, Tourism Geographies, 9(4), 347-370.

Dale, C. J. P. 2013. Kuasa, Pembangunan, dan Pemiskinan Sistemik. Labuan Bajo: Sunspirit Books; bandingkan: Karim, A. 2008. Kapitalisasi Pariwisata dan Marginalisasi Masyarakat di Lombok. Yogyakarta: Genta Press.

Damanik, J. 2005. Penanggulangan Kemiskinan Melalui Pariwisata. Yogyakarta: Kepel Press.

Damanik, J dan Weber H., 2006. Perencanaan Ekowista: Dari Teori ke Aplikasi. Yogyakarta: Penerbit Andi

Demartoto, A. 2009. Pembangunan Pariwisata Berbasis Masyarakat. Surakarta: Sebelas Maret University Press

Fandeli, C. 2002. Perencanaan Kepariwisataan Alam. Yogyakarta: Fakultas Kehutanan UGM.

Giampiccoli, A, Kalis, J. H. 2012. Community-based Tourism and Local Culture: the case of the amaMpondo. PASOS

Goodwin, H, Santilli, R. (2009). Community-Based Tourism: a success? ICRT Occasional Paper 11.

Habibah, A., Hamzah, J., Mushrifah, I. 2010. Sustainable Livelihood of the Community in Tasik Chini Biosphere Reserve: the Local 
Practices, Journal of Sustainable Development, 3(3), 184-196.

Mensah, E. A., Amuquandoh, F. E. 2010. Poverty Reduction through Tourism: Residents' Perspectives. Journal of Travel and Tourism Research, Spring/Fall, 77-96.

Nasikun. 2000. Model Pariwisata Pedesaan :Pemodelan Pariwisata Pedesaan untuk Pembangunan Pedesaaan yang Berkelanjutan. Prosiding Pelatihan dan Lokakarya Perencanaan Pariwisata Berkelanjutan. Bandung : Penerbit ITB.

Pitana, I. G. 1999. Pelangi Pariwisata Bali: Kajian Sosial Budaya Kepariwisataan Bali di Penghujung Abad. Makalah Lomba Kampungku Indah dan Ramah. Denpasar. Penerbit BP Profil Pedukuhan Salam Trumpon.

Pitana, I. G., Gayatri, P.G. 2005. Sosiologi Pariwisata. Yogyakarta : Penerbit Andi.

Putra, H.S.A. 2011. Pariwisata di desa dan Respon Ekonomi: kasus dusun Brayut di Sleman, Yogyakarta: Antropologi Budaya, Fakultas Ilmu Budaya UGM.

Suansri, P. 2003. Community Based Tourism Handbook, Thailand : Responsible Ecological Social Tours (REST) Project.

Sugiyono. 2003. Statistik untuk Penelitian. Bandung: CV.Alvabeta.

Toressa, R, Momsen J.H, 2004. "Challenges and potential for linking torism and agriculture to achieve pro-poor tourism objectives", Progr. in Dev. Stud., 4(4), hal 294-318.

UNEP and WTO. 2005 Making Tourism More Sustainable: a guide for policy makers.

Undang Undang Republik Indonesia Nomor 10 Tahun 2009 tentang Kepariwisataan.

\section{Profil Penulis}

Rosdiana Pakpahan Lahir di Medan pada tanggal 06 Januari 1990. Angkatan 2008 di Akademi Pariwisata Medan dengan jurusan Manajemen Usaha Perjalanan (D3) dan dilanjutkan dengan S1 di Sekolah Tinggi Pariwisata Ambarrukmo Yogyakarta pada tahun 2012 dengan jurusan Hospitality. Kemudian pada tahun 2015 melanjutkan studi kejenjang yang lebih tinggi yaitu S2 di Universitas Gadjah Mada dengan jurusan Kajian Pariwisata. Lulus pada tahun 2017 dengan nilai cumlaude dan sebelum menjadi Dosen di Sekolah Tinggi Pariwisata Pelita Harapan sempat menjadi Tenaga Ahli dibeberapa proyek dari Kementerian Pariwisata. 